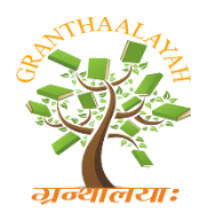
INTERNATIONAL JOURNAL OF RESEARCH
GRANTHAALAYAH
A knowledge Repository

Management

\title{
ASSESSMENT OF PACKAGE GRAPHICS AND COLOUR ATTRIBUTES ON CONSUMERS' BUYING BEHAVIOUR IN KENYA
}

\author{
Betty Jepchirchir Kosgei ${ }^{1}$, Dr. Jane Wanjira ${ }^{2}$ (PhD) \\ ${ }^{* 1,2}$ Department of Business Administration, School of Business, Kenyatta University, Kenya
}

\begin{abstract}
Understanding consumer buying behaviour and their preference to product attributes has become a key success factor in contemporary competitive and rapid changing business environment. Consumer is now more discerning and individualistic requiring marketers to gain insights into their buying behaviour especially the attitude they have towards product innovation especially packaging. The general objective of the study was to determine the effect of packaging attributes on consumer's buying behaviour of packaged foods in Kenya. This paper discusses the research findings on the influence of packaged food graphics and colour attributes on consumers' buying behaviour in Kenya. The study was supported by the Theory of Reasoned Action, the HowardSheth Model and Kano's Theory of Attractive Quality. Descriptive and explanatory research designs were used and a sample of 385 shoppers from three supermarkets in Nairobi was selected randomly while data was collected using structured questionnaires. The selection of supermarkets was based on judgmental sampling in which location and foot traffic was considered. Data was analysed using descriptive statistics in the form of mean, percentages and standard deviations, and inferential statistics in the form of correlation tests and regression analysis. The study found a statistically significant relationship between the attributes of graphics and colour and consumer's buying behaviour. The study recommends that food manufacturers understand consumer response to their packages, and integrate the inputs into designing the best packaging styles. This can be achieved by involving consumers in the process of packaging so that the right decisions are made without making any assumption regarding the final packaging of food products. This study is beneficial to new and existing food product manufacturers in coming up with strategies and in development of product packaging. Keywords: Package Graphics, Colour Attributes, Consumers' Buying Behaviour.
\end{abstract}

Keywords: Package Graphics; Colour Attributes; Consumers' Buying Behaviour.

Cite This Article: Betty Jepchirchir Kosgei, and Dr. Jane Wanjira. (2018). "ASSESSMENT OF PACKAGE GRAPHICS AND COLOUR ATTRIBUTES ON CONSUMERS' BUYING BEHAVIOUR IN KENYA.” International Journal of Research - Granthaalayah, 6(6), 488-497. https://doi.org/10.29121/granthaalayah.v6.i6.2018.1394. 


\section{Introduction}

Stiff competition exists in contemporary environment of business requiring marketers to focus more on understanding consumer behaviour. As explained by Wambugu, Musyoka and Kaluyu (2014) studying buying behaviours of consumers is paramount since; this knowledge helps the manufacturers in planning and implementation of marketing strategies. This knowledge further allows them to select and segment target markets leading to development of appropriate marketing strategies. Further, it allows enterprises to come up with appropriate marketing mix targeting on marketing operations. In addition, when marketers understand the factors affecting the buyers' behaviour, they can predict their response to different marketing strategies. According to Blackwell, Miniard and Engel (2009), knowledge of the consumer buying behaviour and patterns assist marketers in selection and segmentation of the target market which leads to the creation of the right marketing strategies that suits the target market. Several studies have been carried out by Mwongera (2012), Wambugu, Musyoka and Kaluyu (2014), Wambugu (2014) and Karimi, Papamichail and Holland (2010) on factors that affect consumer behaviour.

However, their studies did not focus on the packaging attributes. Many of the studies conducted have focused on Kenyan milk consumption and yet other products exist in the Kenyan market that are packaged and consumed by customers. There are many factors that make a quality product and packaging is one such factor that can transform a good product to a bad one (Africa.com, n.d., para. 2). African manufacturers underestimate the importance of proper packaging and it is often relegated to functional purpose of transport (Africa.com, n.d., para.2). The African consumer is diverse and has different expectations in regard to ease of use, labelling and size of packaging for the product. From the available literature, there is no study that has looked at the effect of packaging on buying patterns and behaviours of consumers in Kenya. Kenyan consumers just like others in the developing and emerging markets expect more as they increase their buying power and future prospects become brighter. If marketers can research on the buying behaviour and patterns of the Kenyan consumer and how packaging changes the perception to the brand, they will be able to secure lifelong customers.

\section{Literature}

\subsection{Product Package Graphics and Consumer Buying Behaviour}

Wells, Farley and Armstrong (2007), in their study on Packaging Design for Own-Label Food Brands, have explored the relationship between packaging and quality perception. Their results showed that more than $43 \%$ of consumers use packet photography as proof of product quality. Therefore, graphics that attract consumers at the point of sale help the consumers make the purchase decision quickly. Karimi (2010) explored the relationship existing between the purchase behaviour and packaging elements of health products, cosmetics and food products in India. The findings showed that there is a significant relationship between the purchase behaviour of the consumers and the product image. However, Karimi (2010) failed to investigate the nexus between the specific package graphics like colour of the product and how they influence consumer behaviour.

Another study by Mizutani, Okamoto, Yamguchi, Kusakabe, Dand and Yamanaka (2010) has shown that juice packages that had images on them had the power to influence the purchased 
decision. Pleasant images were a source of positivity in regard to taste and juice freshness even if some of the images had no relation to the presented juice. The study also concluded that juices that had congruent images were rated to having a better aroma compared to juices with non-congruent images.

The findings were an experimental confirmation that attractive images are efficient in portraying a congruent and pleasant image of the product, the customer will perceive the product in a positive light (Mizutaniet al., 2010). Although the findings of the study contribute significantly to the gist of this paper, they fail to capture the the specific attractive features of the presented images on the product that influence consumer buying behaviour. In another study on the pictorial and textual packaging elements, Tobias Otterbing (2013) has established that if the textual images are placed on the left-hand side they are more likely to be noticed and pictorial images if placed on the right side are more, likely to be noticed. This indicates that not only is attractiveness of graphics important but the placement of textual and pictorial element is also important so that consumers can notice them. This study however fails to unearth the specific attractiveness of the graphics that influence consumer buying behaviour. By using graphics manufacturers help consumers to find their choice products quickly by eliminating clutters and if they are not loyal to one brand the graphics attract the consumers and give them the opportunity to consider purchasing a given product (Silayoi \& Speece, 2004).

However, Lee (2010) has found that graphics on the packaging for convenience goods has no significant relationship with buying decision. Johan and Tobias (2008), in their study, find that all attributes and not just one attribute must be combined to affect purchase behaviour (as cited in Sioutis, 2011). Sioutis (2011) suggests that graphical information is usually misleading hence consumers do not consider pictures on a package when buying.

Product Package Colour and Consumer Behaviour Ares and Deliza (2010) have carried out a research on the influence of various attributes of packaging on the willingness of the consumer to buy chocolate milk desserts. They evaluated if the characteristics influence was affected by the level of involvement the consumer had with the product. Their research findings disclosed that the level of involvement consumers had with the product had an effect on the interest and reaction of the buyer towards the product (Ares \& Deliza, 2010). Package colour and image that were found on the product were the attributes with the highest significance regardless of the consumer involvement with the product. Chocolates that were coloured brown rather than black and those had pictures of milk desserts were associated with positive values meaning that they were more likely to be bought by the consumers.

Additionally, the shape of the package whether round or square did not have a significant effect on the consumer purchasing behaviour in the different segments (Ares \& Deliza, 2010). The importance of colour and image was far much higher compared to the indicated dessert which showed that the packaging played an important role in influencing the perception and purchasing decision of the consumer. Marshall, Stuart and Bell (2006) have investigated the role packaging colour on the selection of the products among kindergarten students considering age and gender across three different categories of products including cereals, drinks and biscuits. The logo and brand information for the three product categories was hidden and were presented with an assortment of nine colours. The children were requested to select a package from each of the group 
of categories for themselves, another item from each of the categories for a girl and another item from each of the categories for a boy. According to the findings there was a high correlation between the choice of the product and favourite colour across the sampled children but the correlations for individuals was much lower. The study showed that the younger children were likely to choose the colours in line with their preferences (Marshall et al., 2006).

Mutti, Hammond, Borland, Cummings and Fong (2011) have surveyed the buying behaviour of current and former smokers in four countries in relation to colour. They found that a fifth of smokers thought that some cigarette brands were less harmful compared to other brands because of colour attributes. The colour on the label was behind this conclusion. Colours such as blue, purple and silver were seen as less harmful compared to black and red colours. Madden et al. (2000) explain that cultures associate different colours with different things and thus their preferences will be biased in line with their culture colour associations. Conversely, Deliya and Parmar (2012) point out that the different colours on the product packaging set off differing moods among the consumers. From the findings of a research done by Lynsey Hollywood (2013), skimmed, whole and semi-skimmed milk are differentiated by consumers on the bases of the packet colours. However, the use of standardized colours did not affect the buying behaviour of the consumer as there was nothing new on the packaging. Products are accepted by buyers if the colours on their packaging are common with other packaged products in a given product class (Hannele \& Harri, 2010). Radical colour changes can result to confusion for consumers as they look for a particular brand (Hannele \& Harri, 2010). However, the findings do not present any specific correlational significance between product colour and consumer buying behaviour.

In a study by Alervall and Saied (2013), a total of seventy five percent of respondents confessed that the major visual factor that affected their purchase behaviour was colour. According to the results, colour had an influence on human psychology and instincts. Ares and Deliza (2010) and Nawaz and Asad (2012) support the importance of Journal of Marketing and Consumer Research ISSN 2422-8451 An International Peer-reviewed Journal Vol.47, 2018 www.iiste.org 3 colour from their studies that found that irrespective of consumers' involvement with the product package, colour is the most important variable. However, Sioutis (2011) differs on the influence of colour to consumer buying behavior. The findings of his study indicate that colour appears to be of low significance. In fact, it is the least significant attribute for all convenience goods. The preferences for the colour appeared to be slightly product oriented. However, participants still stated that calmative colours such as green tend to be healthiness indicators.

\section{Statement of the Problem}

The increased competition in the global market has led retailers and manufacturers to focus on innovation of products so as to gain and maintain a competitive advantage in order to survive. According to different studies product innovation is a good method to improve product packaging, quality among other product characteristics (Kumar \& Steenkamp, 2007). Thus, product innovation is important in ensuring retailers and manufacturers survive in a competitive market (Im, Montoya \& Workman, 2003). Those who present innovative products in the market have a competitive advantage compared to the others. As Kandampully (2002) explains, when it comes to purchase decision, consumers are now more discerning and individualistic engendering interest from many retailers and manufacturers. There are many innovative products in the market which 
has led to differing purchasing behaviour. Consequently, insights in the buying behaviour of consumers can help retailers and manufacturers understand consumer feelings and thoughts on different products and the attitude they have on product innovation before they make the purchasing decision including the innovation used in elements such as packaging, product features and quality among other elements.

According to Kotler and Armstrong (2001), different factors affect the buying behaviour including; psychological, cultural, personal and social). How culture influences consumer behaviour is different in various countries thus marketers need to be careful in their analysis of different groups, regions and countries culture (Christ, 2009). Locally, Wambugu (2014) focused on the attitude towards milk packaging designs in Kenya. However according to marketing theory, preference and attitude towards a product does not indicate the actual outcome of consumer behaviour. Critics argue that consumers may indicate preference for a commodity or a favourable attitude towards a product, but this may not actually translate to purchase (Blackwellet al., 2009). Mwongera (2012) investigated factors influencing milk consumption in Kenya. However, the study was not carried out at the point of sale. These studies focused on the general influence of packaging and the attitude towards packaging of milk products only. Although the surveys conducted have attempted to examine the link between packaging attributes and consumer behaviour, few of the studies have focused on the African consumer, specifically Kenyans.

The findings from the researches cannot be used in Kenya since consumers around the world are different and their behaviour is not static, it is influenced by various factors which affects their preference of goods and services. The study, therefore, sought to fill this research gap by examining the effect of packaging attributes on consumer buying behaviour of packaged foods.

\section{Methodology}

The type of investigation used was a correlation study, which involves examining the relationship between product quality and the rate of product turnover. Ninety two (92) copies of questionnaire were administered to manufacturing firms adopting the survey research design.

\section{Data Analysis}

\subsection{Effects of Product Quality on Product Turnover}

Table 1: Summary of regression analysis result showing the effects of product quality on product turnover

\begin{tabular}{|l|l|l|l|l|l|l|l|l|l|}
\hline Variables & coef & t-cal & Sig.t & $\begin{array}{l}\text { t-tab } \\
\mathbf{( 0 . 0 5 , 9 0 )}\end{array}$ & $\mathbf{r}$ & $\mathbf{r}^{\mathbf{2}}$ & F-cal & $\begin{array}{l}\text { F-tab } \\
\mathbf{( 0 . 0 5 , 9 0 )}\end{array}$ & p-value \\
\hline Constant & 2.417 & 3.504 & 0.001 & & & & & & \\
\cline { 1 - 3 } & .323 & 25.892 & 0.000 & 1.9 & 0.94 & 0.88 & 670.41 & 3.94 & 0.000 \\
\hline
\end{tabular}

Dependent Variable; Product Turnover

Source: Field survey,2 018

Table 1 showed that the coefficient of correlation is 0.94 . This indicates a very strong positive relationship between product quality and product turnover. The F-cal $=680.414>$ F-tab $(0.05,1$, 
$91)=3.94 ; \mathrm{t}$-cal $=25.892>\mathrm{t}$-tab $(0.05,90)=1.96$ had a corresponding significant $\mathrm{p}$-value of 0.000; showed that product quality has a strong significant influence on the outcome of product turnover. Further analysis of identifying the cumulative effect of dimensions of product quality (performance, product conformance, product serviceability, products aesthetic and product perceived quality) on product turnover is shown in Table 2.

Table 2: Summary of effect of product performance, product conformance, product serviceability, products aesthetic and product perceived quality on product turnover

\begin{tabular}{|c|c|c|c|c|c|c|c|c|c|}
\hline Variables & coef & t-cal & Sig.t & $\begin{array}{l}\text { t-tab } \\
(0.05,90)\end{array}$ & $\mathbf{R}$ & $\mathbf{R}^{2}$ & F-cal & $\begin{array}{l}\text { F-tab } \\
(0.05,90)\end{array}$ & p-value \\
\hline Constant & 1.308 & 2.447 & 0.016 & \multirow{6}{*}{1.96} & \multirow{6}{*}{0.991} & \multirow{6}{*}{0.982} & \multirow{6}{*}{919.992} & \multirow{6}{*}{2.31} & \multirow{6}{*}{0.000} \\
\hline $\mathrm{PP}$ & .0 .098 & 2.409 & 0.163 & & & & & & \\
\hline $\mathrm{PC}$ & .277 & 2.001 & .049 & & & & & & \\
\hline PS & .427 & 5.911 & .000 & & & & & & \\
\hline PA & 1.054 & 10.021 & .000 & & & & & & \\
\hline PPQ & .303 & 2.889 & .000 & & & & & & \\
\hline
\end{tabular}

Dependent Variable; Product Turnover

Source: Field survey, 2018

The result in Table 2 showed that the multiple correlation coefficient is 0.991 . It indicates that a very strong significant relationship exist between the dimensions of product quality and product turnover. The coefficient of determination $(\mathrm{R} 2)=0.982$. It implies that $98.2 \%$ variation in product turnover is explained by variations in product performance, product conformance, product serviceability, product aesthetic and product perceived quality. The F-calculated of $919.992 \mathrm{had}$ a corresponding significant $\mathrm{f}$-value of 0.000 ; the researcher therefore concludes that the model is useful. Conventionally F-Cal $=919.992>$ F-tab $(0.05,5,91)=2.31$ hence the decision above is upheld. Comparatively each of the dimensions of product quality has a significant effect on product turnover; and in a pool bears more influence on product turnover, than what each isolated aspect of product quality.

\section{Discussion}

Product performance refers to operating characteristics of a product as an aspect of product quality which combines both product and user evaluations in the inert characteristics of the product.

However, quality product acceptance differences are perceived as quality differences depending on individual preferences of consumers. Consumers have a wide range of interests and needs, each likely to equate quality with high performance in his or her area of interest (Hajjat, and Hajjat, 2014). The analysis in Table 2 showed that product performance has a t-cal value of $2.409>\mathrm{t}$-tab 1.96, which indicate a positive and significant relationship between product performance and product turnover. This finding supports the view that consumers tend to attribute particular preference to particular product classes by learning the differences between the performances of those products.

More so, the performance of products can play roles in customers' response and purchasing behaviour. Rundh (2005) noted that, quality attracts consumers' attention to a particular product, 
and influences consumers' perceptions of such product. Again, it serves as differentiation, that is, it helps consumers to choose from wide range of similar products and stimulates their buying behaviour (Wells, Farley and Armstrong, 2007). As indicated in Table 2, product conformance revealed a t-cal $2.001>\mathrm{t}$-tab 1.96 signifying that product conformance has effect on product turnover. Justifying this, Garvin, (2007) pointed out that product that conforms to design specifications is primarily process oriented, in that it reflects how well the product and its individual components meet the established standards in satisfying the customers.

Also, another dimension of product quality is serviceability as most consumers use this as a criterion for product selection (Hajjat, and Hajjat, 2014). Customers are concerned not only about a product breaking down, but also the elapsed time before service is restored and the timeliness with which service appointments are kept (Drozdenko and Jensen, 2005). Again, the analysis in Table 2 showed t-cal $5.911>$ t-tab 1.96, which confirm that also serviceability of a product affect product turnover justifying the view of Stevenson (2012) that dimensions of serviceability such as service warranty, length of time customers wait for service appointment, schedule of preventive maintenance, information regarding repairs, all influence the rate of purchase which ultimately affect the product turnover. Consumers can value the look' of a product purely for its own sake, as looking at something beautiful is rewarding in itself. When product alternatives are similar in functioning and price, consumers will prefer the one that appeals the most to them aesthetically. The analysis in Table 2 showed a t-cal of $10.021>t$-tab 1.96, hence product appearance (aesthetics) can provide value in itself as many customers like to buy a product that looks aesthetically pleasing. As product aesthetics influences consumers, evaluation is often complex for manufacturers to understand what consumers really want and produce quality products that are appealing in appearance. Another dimension of product quality assessment is perceived quality.

The perception of quality can be as subjective as assessments of aesthetics, because consumers do not always possess complete information about a product's attributes as they frequently rely on indirect measures when comparing brands. In these circumstances, products will be evaluated less on their objective characteristics than on their images or brand name. Both reputation and the historical strength of a product are important in explaining the ranking of a product based on its Again, the analysis in Table 2 showed t-cal of $2.889>\mathrm{t}$-tab 1.96 indicating that perceived quality affect product turnover. Customers assume that higher prices imply higher quality, but this is not always the case when other factors such as brand name, product image, product features and country of origin influence consumer perception. Thus, if customers perceive a product to be of good quality their buying behaviour results in higher turnover. Conclusion Achieving high product turnover requires that Production managers have access to marketing information on quality specifications in producing quality products that will invoke re-purchase behaviour in consumers to increase the product turnover of the organization. Products that conform to specific design to suite consumers' expectations are likely to steal their heart and in turn increase patronage which results in high product turnover. More so, poor quality products have negative consequences on product turnover, in the sense that it repels consumers from re-purchasing the product. Since low quality product does not provide the required utility for the consumers improvement in product conformance will bring about an increase in product turnover. Also, effective product serviceability and user friendly products will likely result in high turnover rate of manufacturing firms. Thus, manufacturing firms should have effective customer care unit that provides pre- and 
post- purchase services. Again, products with bright colours are valued aesthetically more with higher perceived value inducing consumers buying the product leading to high turnover rate.

Also, another dimension of product quality is serviceability as most consumers use this as a criterion for product selection (Hajjat, and Hajjat, 2014). Customers are concerned not only about a product breaking down, but also the elapsed time before service is restored and the timeliness with which service appointments are kept (Drozdenko and Jensen, 2005). Again, the analysis in Table 2 showed t-cal 5.911 > t-tab 1.96, which confirm that also serviceability of a product affect product turnover justifying the view of Stevenson (2012) that dimensions of serviceability such as service warranty, length of time customers wait for service appointment, schedule of preventive maintenance, information regarding repairs, all influence the rate of purchase which ultimately affect the product turnover. Consumers can value the look' of a product purely for its own sake, as looking at something beautiful is rewarding in itself. When product alternatives are similar in functioning and price, consumers will prefer the one that appeals the most to them aesthetically. The analysis in Table 2 showed a t-cal of $10.021>t$-tab 1.96, hence product appearance (aesthetics) can provide value in itself as many customers like to buy a product that looks aesthetically pleasing. As product aesthetics influences consumers, evaluation is often complex for manufacturers to understand what consumers really want and produce quality products that are appealing in appearance. Another dimension of product quality assessment is perceived quality. The perception of quality can be as subjective as assessments of aesthetics, because consumers do not always possess complete information about a product's attributes as they frequently rely on indirect measures when comparing brands. In these circumstances, products will be evaluated less on their objective characteristics than on their images or brand name. Both reputation and the historical strength of a product are important in explaining the ranking of a product based on its Again, the analysis in Table 2 showed t-cal of $2.889>$ t-tab 1.96 indicating that perceived quality affect product turnover. Customers assume that higher prices imply higher quality, but this is not always the case when other factors such as brand name, product image, product features and country of origin influence consumer perception. Thus, if customers perceive a product to be of good quality their buying behaviour results in higher turnover. Conclusion Achieving high product turnover requires that Production managers have access to marketing information on quality specifications in producing quality products that will invoke re-purchase behaviour in consumers to increase the product turnover of the organization. Products that conform to specific design to suite consumers' expectations are likely to steal their heart and in turn increase patronage which results in high product turnover. More so, poor quality products have negative consequences on product turnover, in the sense that it repels consumers from re-purchasing the product. Since low quality product does not provide the required utility for the consumers improvement in product conformance will bring about an increase in product turnover. Also, effective product serviceability and user friendly products will likely result in high turnover rate of manufacturing firms. Thus, manufacturing firms should have effective customer care unit that provides pre- and post- purchase services. Again, products with bright colours are valued aesthetically more with higher perceived value inducing consumers buying the product leading to high turnover rate.

\section{Conclusion}

Achieving high product turnover requires that Production managers have access to marketing information on quality specifications in producing quality products that will invoke re-purchase 
behaviour in consumers to increase the product turnover of the organization. Products that conform to specific design to suite consumers' expectations are likely to steal their heart and in turn increase patronage which results in high product turnover. More so, poor quality products have negative consequences on product turnover, in the sense that it repels consumers from re-purchasing the product. Since low quality product does not provide the required utility for the consumers improvement in product conformance will bring about an increase in product turnover. Also, effective product serviceability and user friendly products will likely result in high turnover rate of manufacturing firms. Thus, manufacturing firms should have effective customer care unit that provides pre- and post- purchase services. Again, products with bright colours are valued aesthetically more with higher perceived value inducing consumers buying the product leading to high turnover rate.

\section{References}

[1] Akinola, J., Akinradewo, O. \& Olatunji, S. (2012). Impact of Total Quality Management (TQM) on Nigerian construction firms. Proceedings of the 4th West Africa Built Environment Research (WABER) Conference, 24-26 July, Abuja, Nigeria.

[2] Bagshaw, K.B (2017) Process and product design: production efficiency of manufacturing firms in Rivers State, Nigeria, Engineering Management Research; 6 (1), 49-55.

[3] Cronin, J.J., \& Taylor, S.A. (1992). Measuring service quality: a re-examination quality procedures in service industry, Journal of Quality Assurance, 12 (3), 34 -49. Devra, G. (2015), Relationship between Inventory Turnover \& Purchasing Need. Demand Media.

[4] Drozdenko, R. and Jensen, M. (2005). Risk and maximum acceptable discount levels. Journal of Product and Brand Management, 14 (4), 264-270.

[5] Euphemia F.T.Y \& Sian S.L.C (2010). "The Effect of Retail Service Quality and Product Quality on Customer Loyalty", Journal of Database Marketing and Customer Strategy Management, 17(3): 222-240.

[6] Fandos, C. \& Flavian C (2006). Intrinsic and extrinsic quality attributes loyalty and buying intention: an analysis for a PDO product, British Food Journal, 108(8), 646-662.

[7] Fox, E.J., Montgomery, A.L. \& Lodish, L.M. (2004). Consumer shopping and spending across retail formats. Journal of Business, 77 (2), 25-60.

[8] Garvin, D. A., 1987: What does product quality really mean? Sloan Management Review. 26, (1), 25-43. Garvin, D. A., 2007: Competing on the eight dimensions of quality. Harvard Business Review.65, (6), 101-109. Gunasekaran, A. (1999). Enablers of Total Quality Management Implementation in Manufacturing: A Case Study. Total Quality Management, 10(7), 987-996.

[9] Gustafsson, A., Ekdahl, F. and Edvardsson, B. (1999). Customer focused product development in practice - A case study at Scandinavian Airlines System (SAS). International Journal of Service Industry Management, 10(4), 344-358.

[10] Hajjat, M.M \& Hajjat, F. (2014) The effect of product quality on business performance in some Arab companies, Journal of Emerging Trends in Economics and Management Sciences, 5(5):498508.

[11] Holbrook, M.B. (1994). The nature of customer value: an axiology of services in the consumption experience in Rust, R.T., \& Oliver, R.L. (Eds), Service Quality: New Directions in Theory and Practice, Sage, Thousand Oaks, CA, 21-71.

[12] Ignatio, M., Lovemore, K. \& Chancellor C. (2013). Application of Just In Time (JIT) Manufacturing Concept in Aluminum Foundry Industry in Zimbabwe. International Journal of Science and Research, India, 2(2).25 - 42 Ishikawa, K. (211). Introduction to quality control. Tokyo: 3A Corporation. 
[13] Japan, Julian, P. \& Syed, A. (2014), 'Quality Management Implementation and quality of production in Malaysia's Manufacturing companies. International Journal of Research in Business Management. 2(3), 53-60 Kano, N. (2001). Life cycle and creation of attractive quality. 4th international conference of quality management and organisational development, Sweden: Linkoping University.

[14] Kano, N., Seraku, N., Takahashi, F. and Jui, S. (1984). Attractive quality and must-be quality. Hinshitsu, 14 (2), 147-156

[15] Llusar, J.C.B, Zornoza, C.C, Tena, A.B.E (2001). Measuring the relationship between firm perceived quality and customer satisfaction and its influence on purchase intentions. Total Quality. Management. 12(6): 719-734.

[16] Madu C, Kuei C, \& Lin, C (1995). A comparative analysis of quality practice in manufacturing firms in the US and Taiwan. Decision, Science. 26-35.

[17] Marijan, E., Ivan, J. \& Maja, H. (2013), Business Logistics in Modern Management. International Scientific conference. Faculty of economics, University of josip juraj strossmayer, Osijek.

[18] Neil, L. (2011). Pricing Strategies for Emerging Markets. Nature Reviews Drug Discovery. Nature Publishing Group, 10 (2) 36 - 49. Olaleke, O. (2010). Assessing the relationship between service quality and customer satisfaction; evidence from Nigerian banking industry, Global Journal of Management and Business Research, 10(3), 2-7.

[19] Opoko, A., Ezema, I. \& Ediae, O. (2014). Implementation of Quality-Management Procedures in the Production and Utilization of Cement Stabilized Laterite Interlocking Blocks in Nigeria. Covenant Journal of Research in the Built Environment. 1(1) 23-38.

[20] Ozaki, R. (2003). Customer focused Approaches to Innovation in House Building. Journal of Construction Management and Economics, 557 - 564.

[21] Rachel, Y., Andy, Y., \& Edwin, C. (2008). The Impact of employee satisfaction on quality and profitability in high-contact service industries. Journal of Operations Management, 26 (8) 651-668.

[22] Rundh, B. (2005). The multi-faceted dimension of packaging, marketing logistic or marketing tool? British Food Journal, 107(9), 670-684.

[23] Schonberger, R (2003), World Class Manufacturing Casebook: Implementing JIT and TQC. New York. The Free Press.

[24] Shaharudin, J., Angelyn, G., Johari, A. \& Khin, T. M, (2012) Examining the Product Quality Attributes That Influences Customer Satisfaction Most When the Price Was Discounted: A Case Study in Kuching Sarawak, International Journal of Business and Social Science, 3(23), 221-236.

[25] Slack, N., Chambers, S., Harland, C., Harrison, A., Johnston, R., (2010) Operations management, 2nd edition, Pitman Publishing, London, UK.

[26] Stevenson, W.J. (2012). Introduction to management science, 3rd ed. Burr Ridge, IL. Richard D.

[27] Irwin Tan, G. \& Sia, L. (2001). ISO 9000: The Answer for Total Quality Management Implementation? The Malaysian Case. Total Quality Management, 12(2), 223-229.

[28] Tjiptono, F \& Chanra, G. (2011). Service, Quality \& Satisfaction. Yogyakarta: Andi.Tokyo.

[29] Tsiaotso R (2005). Perceived quality levels and their relation to involvement, satisfaction, and purchase intentions. Retrieved from http://marketing-bulletin.massey.ac.nz. Mark. Bull., 16: 1-10. Verhoef, P. C., \& Lemon, K. C. (2013). Successful customer value management: Key lessons and emerging trends. European Management Journal, 3(1), 1-15

[30] Watson G. (2003). Customer focus and competitiveness. Journal of Business and Management, 3 (7), 54-61.

[31] Wells I., Farley H., and Armstrong G. (2007). The importance of packaging design for own-label food brands. International Journal of Retail and Distribution Management, 35 (9), 677-690.

[32] Yusof, S. and Aspinwall, E. (2000). Critical Success Factors for Total Quality Management Implementation in Small and Medium Enterprises. Total Quality Management, 10(4/5), 803-809.

\footnotetext{
*Corresponding author.

E-mail address: albertphd1986@ gmail.com
} 